sult can potentially be due to the low resolution in our record. On the other hand, this result also raises the question whether Holocene climatic signals from archives in ENSO-sensitive regions contain non-ENSO signals, such as seasonally-induced InterTropical Convergence Zone migrations.

Most reconstructions of past changes in climatological parameters linked to ENSO activity do not account for the potential impact of past seasonality. Yet seasons can have a considerable impact on the geological record of past climate (Leduc et al., 2010; Laepple and Lohmann, 2009). We emphasize that a careful examination of records of past hydrologi- cal changes from oceanic regions without seasonal cycles, together with sampling strategies collecting the full spectrum of hydrological variability within the time intervals studied, would help to clarify which climatic phenomenon modulates the first-order climatic signal archived in geological records.

\section{Acknowledgements}

This study benefitted from thorough insights provided by one anonymous reviewer.

\section{Data}

The data are available on the World Data Center on the NOAA website at ftp://ftp.ncdc.noaa. gov/pub/data/paleo/contributions_by_author/leduc2009/leduc2009.txt

\section{References}

Koutavas, A., deMenocal, P.B., Olive, G.C. and Lynch-Stieglitz, J., 2006 Mid-Holocene El Niño-Southern Oscillation (ENSO) attenuation revealed by individual foraminifera in eastern tropical Pacific sediments, Geology, 34: 993-996.

Laepple, T. and Lohmann, G., 2009: Seasonal cycle as a template for climate variability on astronomical timescales, Paleoceanography, 24: PA4201, doi:10.1029/2008PA001674.

Leduc, G., Vidal, L., Cartapanis, 0. and Bard, E., 2009(a): Modes of eastern equatorial Pacific thermocline variability: Implications for ENSO dynamics over the last glacial period, Paleoceanography, 24 PA3202, doi:10.1029/2008PA001701

Leduc, G., Vidal, L., Tachikawa, K. and Bard, E., 2009(b): ITCZ rather than ENSO for abrupt climate changes across the tropical Pacific? Quaternary Research, 72: 123-131.

Leduc, G., Schneider, R., Kim, J.-H. And Lohmann, G., 2010: Holocene and Eemian Sea surface temperature trends as revealed by alkenone and $\mathrm{Mg} / \mathrm{Ca}$ paleothermometry, Quaternary Science Reviews, doi:10.1016/j.quascirev.2010.01.004, in press.

\title{
Southern Hemisphere intermediate water formation and the bi-polar seesaw
}

\author{
Simon J.A. Jung ${ }^{1}$, D. Kroon ${ }^{1}$, G. Ganssen² ${ }^{2}$, F. Peeters ${ }^{2}$ and R. Ganeshram ${ }^{1}$ \\ 'School of GeoSciences, The Grant Institute, Edinburgh, UK; simon.jung@ed.ac.uk \\ Department of Paleoecology \& Paleoclimatology, Faculty of Earth and Life Sciences, Vrije Universiteit Amsterdam, The Netherlands.
}

\section{Periodic intensifications of Antarctic Intermediate Water flow occurred as part of the millennial-scale climate oscillations in the glacial period.}

During the last glacial period, a profound millennial-scale climate variation prevailed. First discovered in Greenland ice cores, it has subsequently been documented around the globe, yet the underlying mechanisms controlling this variability have not been indentified. Adding to the complexity of this rapid climate change is an interhemispheric asynchronicity, known as the bipolar seesaw. A significant clue towards unraveling the controls of millennialscale variability came from the deep ocean off Portugal (Shackleton et al., 2000). Here, stable oxygen isotope variability in surface dwelling planktic foraminifera shows clear ties to Greenland climate variability, whereas the respective record based on benthic foraminifers living on the seafloor relates to Antarctic climate variation, reflecting the southern origin of the Antarctic Bottom Water that prevails in the abyssal Atlantic off Portugal.

One likely mechanism for the climatic asynchronicity involves an interhemispheric imbalance in heat storage (Stocker and Johnsen, 2003). Surface ocean records from the South Atlantic Ocean (Barker et al., 2009) indeed show a climate change pattern opposed to that in Greenland ice cores supporting the view that asynchronous heat storage is instrumental in off-setting Northern and Southern Hemisphere climate change at the millennial-scale.

The role of southern-source intermediate water (Antarctic Intermediate Water,
AAIW) in the bipolar seesaw is of global relevance due to its large volume and associated energy storage capacity. However, data-based evidence is rare. Benthic stable isotope data from the intermediate depth SW Pacific (Pahnke and Zahn, 2005) show periods of intensified glacial AAIW formation during the cold Heinrich Events in the North Atlantic. During Heinrich Events, the large continental ice masses surrounding

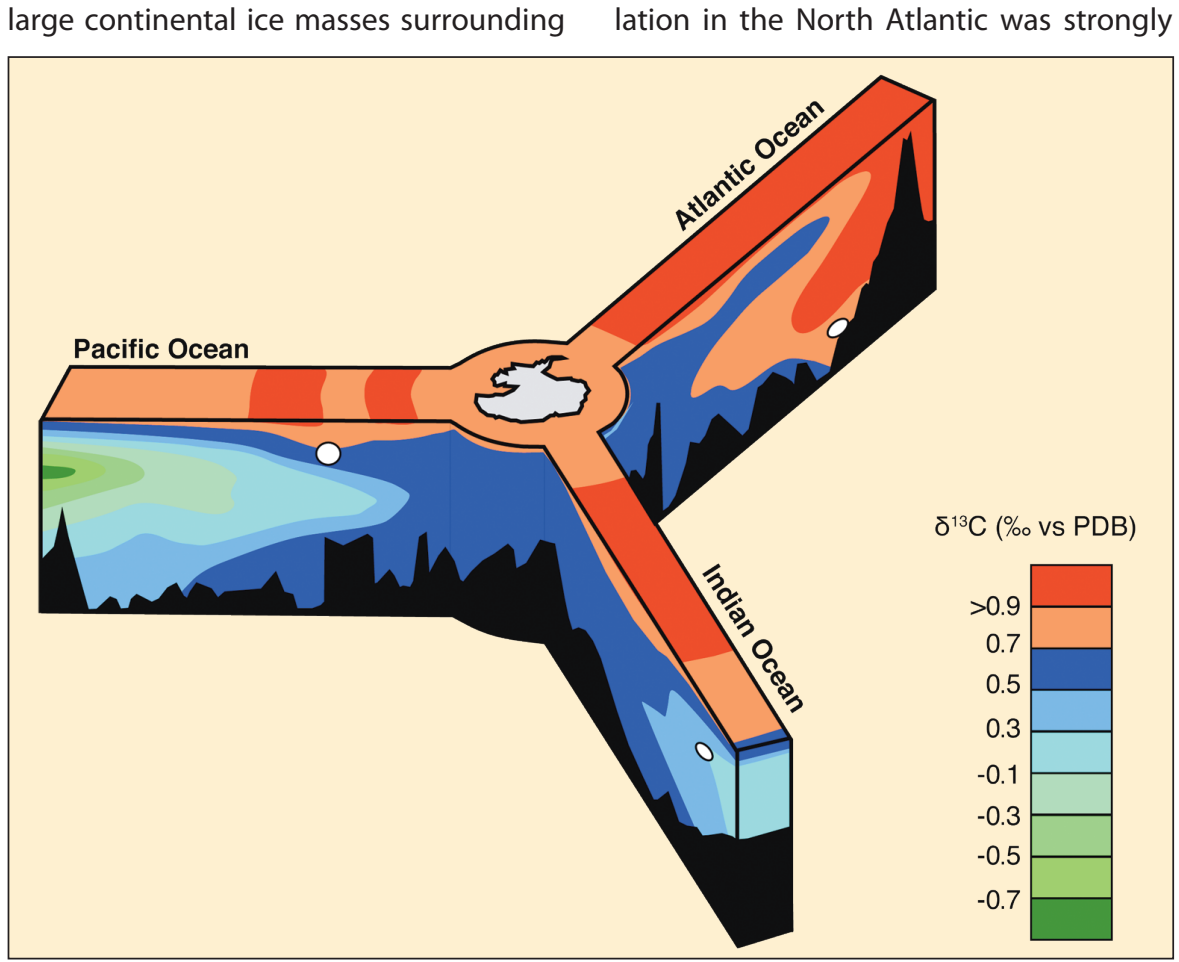

Figure 1: Distribution of $\delta^{13} \mathrm{C}$ in the modern ocean (redrawn from Charles and Fairbanks, 1992). White circles indicate the location of sediment cores NIOP 905 (Indian Ocean; Jung et al., 2009), MD95-2042 (Atlantic Ocean; Shackleton et al., 2000) and MD97-2120 (Pacific Ocean; Pahnke and Zahn, 2005). 
reduced. To assess the wider implications of these findings, glacial AAIW records from other parts of the world ocean, such as the Indian Ocean, are required.

To assess the millennial-scale changes in surface and intermediate waters in the northern Indian Ocean and their relation to the bipolar seesaw, we studied core NIOP 905 collected off the coast of Somalia (Fig. 1) from a water depth of $\sim 1580 \mathrm{~m}$, and compared it with Greenland and Antarctic ice core records. The $\delta^{15} \mathrm{~N}$ and the planktic $\delta^{18} \mathrm{O}$ records in Figure 2 largely reflect variations in surface seawater properties. The benthic $\delta^{18} \mathrm{O}$ and $\delta^{13} \mathrm{C}$ isotope records, however, reflect the intermediate water history in the region.

Both, the $\delta^{15} \mathrm{~N}$ and $\delta^{18} \mathrm{O}$ show that the sea surface history in the Arabian Sea strongly resembles Greenland climate change (Fig. 2a, c). Accordingly, they were used to tie the Arabian Sea core to the Greenland ice-core timescale. Striking new results are that 1) surface ocean and intermediate depth changes occur out-ofphase (Fig. 2c, d) and 2) the intermediate water variability shows a close relation with Antarctic climate history (Fig. 2d, f), hence hosting evidence for a bi-polar seesaw pattern. Whilst the surface ocean change reflects Northern Hemisphere climate change, the Intermediate Water record seems to be tied to that in the south.

The benthic $\delta^{13} \mathrm{C}$ record of core NIOP 905 (Fig. 2e) can be used as a proxy for the age of a water mass along its flow path because of the continuous remineralization of isotopically light detrital organic matter. This process results in lower levels of $\delta^{13} \mathrm{C}$ in the dissolved carbon pool (see Jung et al., 2009) for full discussion; compare Fig. 1). The $\delta^{13} \mathrm{C}$ results from core NIOP 905 show peak values during Heinrich Events (Fig. $2 \mathrm{e})$, implying that $\delta^{13} \mathrm{C}$ changes in the intermediate depth Indian Ocean were antiphased with those of deep water in the Atlantic Ocean. That is, when the overturning circulation in the Atlantic Ocean was reduced during the Heinrich periods, enhanced intermediate water flow occurred in the Northern Indian Ocean. Periodic advection of a southern source intermediate water mass such as glacial AAIW may explain our data.

To date, AAIW forms primarily in the southeastern Pacific and the southwestern Atlantic Ocean (Sloyan and Rintoul, 2001). Today, the AAIW does not reach the northern Indian Ocean (Fig. 1). In the absence of intermediate water formation locally in the glacial northern Indian Ocean (for full discussion see Jung et al., 2009) the most likely explanation for our new data involves a change in intermediate water formation

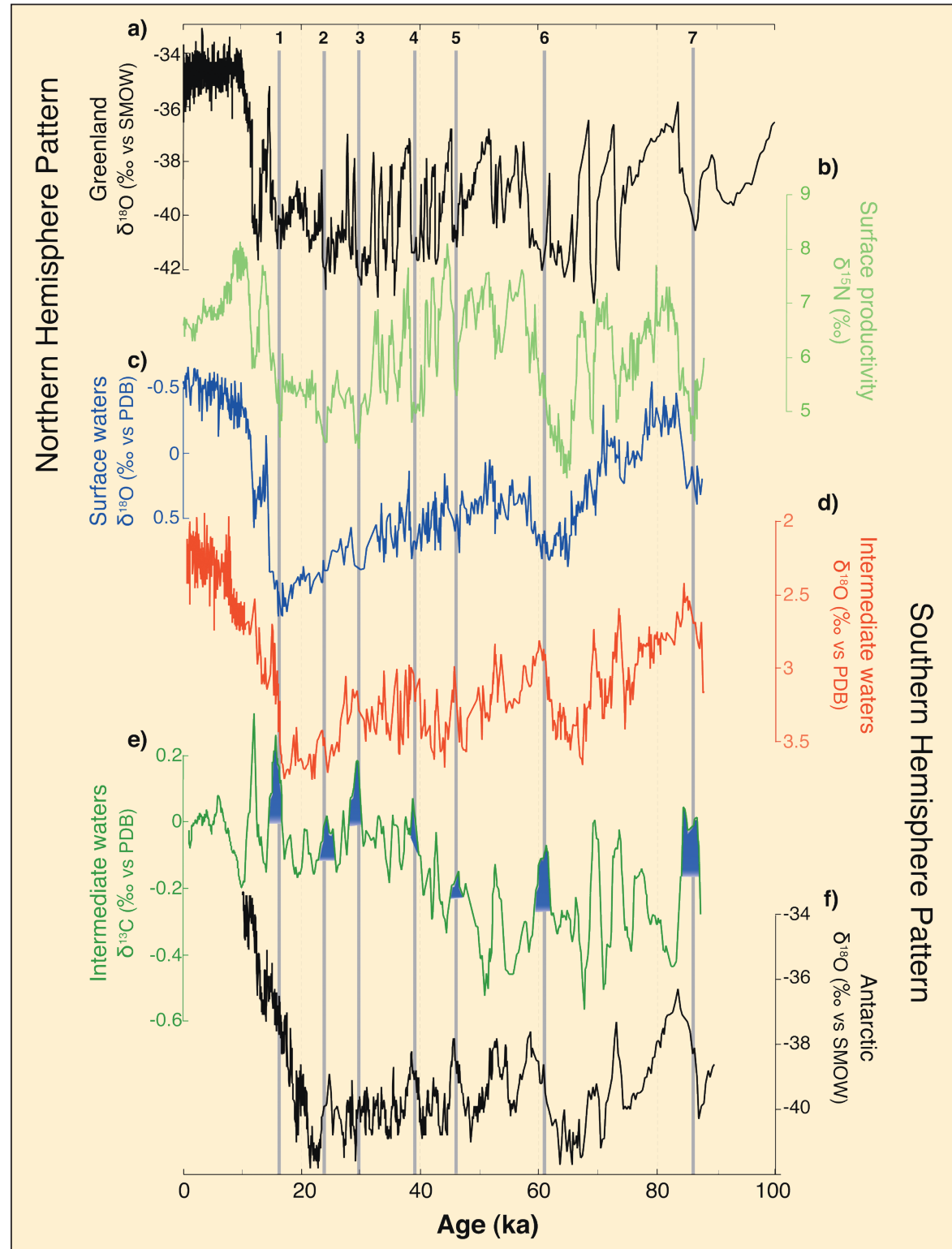

Figure 2: Comparison of (top to bottom) a) the stable oxygen isotope record of the Greenland GISP ice core (Blunier and Brook, 2001, and references therein), b) the $\delta^{15} \mathrm{~N}$ record of core NIOP 905 (see Fig. 1 for location), a proxy for surface water productivity, c) $\delta^{18} \mathrm{O}$ record of the planktic foraminifer Neogloboquadrina dutertrei from core NIOP 905 , reflecting variations in surface waters (Ivanochko et al., 2005), d) the oxygen and e) carbon isotope records of the epibenthic foraminifer Cibicidoides kullenbergi from core NIOP 905, reflecting variations in intermediate waters (Jung et al., 2009), and $\boldsymbol{f}$ ) $\delta^{18} \mathrm{O}$ record from Byrd Ice Core, Antarctica. Vertical gray bars indicate the timing of the North Atlantic Heinrich Events. Blue shaded areas indicate periods of increased ventilation of intermediate water. The age model of core NIOP 905 is constrained by 24 AMS ${ }^{14} \mathrm{C}$ dates (Ivanochko et al., 2005). Beyond the reach of the radiocarbon method, the NIOP 905 records were aligned with Greenland climate change, in line with previous results from the Arabian Sea (Altabet et al., 2002; Schulz et al., 1998).

in the Southern Hemisphere. Both the similarity in timing between Antarctic climate change (Blunier et al., 1998; EPICA, 2006) and the intermediate water oxygen isotope variability off Somalia (Fig. 2) together with the almost simultaneous changes in benthic $\delta^{13} \mathrm{C}$ and $\delta^{18} \mathrm{O}$ values (Fig. 2), support the notion that episodically enhanced formation of glacial AAIW has reached the northern Indian Ocean.

During periods of enhanced glacial AAIW flow ( $\left({ }^{13} \mathrm{C}\right.$ maxima in Fig. 2e), minima in the benthic oxygen isotope record (Fig. 2d) reflect warming of intermediate water in the source regions of glacial AAIW in the Southern Hemisphere. Part of the oxygen isotope change, however, is due to changes in ice volume. While roughly half of the oxygen isotope change reflects variations in global ice volume (Shackleton et al., 2000), the remaining $\delta^{18} \mathrm{O}$ reduction equals a temperature rise of up to $2^{\circ} \mathrm{C}$, in line with an earlier study on intermediate water temperature in the Pacific Ocean (Stott et al., 2007).

Evidence of enhanced glacial AAIW flow during periods of near-collapsed meridional overturning circulation in the North Atlantic is crucial for the understanding of the bipolar seesaw. At times of maximum cold conditions in the North Atlantic, the $\delta^{18} \mathrm{O}$ records suggest that the intermediate water layers in the Indian (Jung et al., 2009) and SW Pacific Ocean (Pahnke and Zahn, 2005), fed by glacial AAIW, have warmed. If true, this might have implications for climate change around Antarctica and in the North Atlantic region. First, 
excess heat storage in glacial AAIW would have reduced the energy available for heating the atmosphere in the sub-/polar Southern Hemisphere and consequently attenuated the millennial-scale warm events over Antarctica. Second, by temporarily warming glacial AAIW, the amount of energy/heat available for equilibrating interhemispheric energy imbalances was reduced. This supports the notion that excess heat storage in glacial AAIW might have been instrumental in maintaining cold conditions in the North Atlantic.

The timing of the glacial AAIW warm events seems to point to a specific sensitivity of the climate system as a whole to changes in AAIW formation. It is currently difficult to substantiate the specific role of AAIW in the bipolar seesaw. Given the mounting evidence reflecting the wider significance of Southern Hemisphere climate change, it is increasingly likely that variations in the ocean-atmosphere dynamics in this part of the world exert a profound control on climate change on a global scale. This would contrast with the view of a rather "passive" role of the Southern Hemisphere, i.e., largely responding to climate changes triggered elsewhere.

\section{Data}

Data are stored at the National Climate Date Center, Boulder, Colorado (http://www.ncdc.noaa. gov/paleo/data.html).

\section{References}

Altabet, M.A., Higginson, M.J. and Murray, R.W., 2002: The effect of millennial-scale changes in the Arabian Sea denitrification on atmospheric $\mathrm{CO}_{2}$, Nature, 415: 159-162.

Barker, S., Diz, P., Vautravers, M., Pike, J., Knorr, G., Hall, I.R. and Broecker, W.S., 2009: Interhemispheric Atlantic seesaw response during the last deglaciation, Nature, 457: doi:10.1038/nature07770.

Blunier, T. and Brook, E.J., 2001:Timing of millennial-scale climate change in Antarctica and Greenland during the last glacial period, Science, 291: 109-112.

Ivanochko, T.S., Ganeshram, R.S., Brummer, G.-J.A., Ganssen, G., Jung, S., Moreton, S.G. and Kroon, D., 2005: Variations in tropical convection as an amplifier of global climate change at the millennial scale, Earth and Planetary Science Letters, 235: 302-314.

Jung, S.J.A., Kroon, D., Ganssen, G., Peeters, F. and Ganeshram, R., 2009 Enhanced Arabian Sea intermediate water flow during glacial North Atlantic cold phases, Earth and Planetary Science Letters, 280: $220-228$

For full references please consult:

http://www.pages-igbp.org/products/newsletters/ref2010_1.htm

\section{The $2^{\text {nd }}$ PAGES past interglacials workshop}

\section{Mytilene, Greece, 24-27 August 2009}

\section{Chronis Tzedakis $^{1,2}$, D. Raynaud ${ }^{3}$ and J.F. McManus ${ }^{4}$}

'Department of Geography, University College London, UK; p.c.tzedakis@ucl.ac.uk; 2Department of Environment, University of the Aegean, Mytilene, Greece; ${ }^{3}$ Laboratoire de Glaciologie et Géophysique de l'Environnement, Grenoble, France; ${ }^{4}$ Lamont-Doherty Earth Observatory, Columbia University, USA

In the context of future climate change, there is a need to understand the sensitivity of the Earth System to different forcings. Though not strict analogues for an anthropogenic future, past interglacials can be thought of as a series of natural experiments in which boundary conditions varied considerably, with consequent effects on the character of climate change. Their examination, therefore, can provide a more complete view of the range and underlying physics of natural climate variability. Examination of the paleoclimate record reveals a large diversity between interglacials in terms of their intensity, duration and internal variability. This raises fundamental questions about the Earth's climate, but a general theory accounting for the occurrence of interglacials with differing characteristics remains elusive (Tzedakis et al., 2009). This has provided the impetus for a comprehensive comparison of interglacials of the last $800 \mathrm{ka}$ within the context of the PAGES Working Group on Past Interglacials (PIGS).

The first PIGS workshop, held at Bernin, France, 2-4 October 2008, defined specific priority topics, which would form the themes of three subsequent workshops: (1) intra-interglacial variability; (2) magnitude and duration of interglacials; and (3) explaining the structure of interglacials from the forcing. The overall aim is to integrate the various themes emerging from the workshops in order to arrive at an improved understanding of the factors determining interglacial diversity.

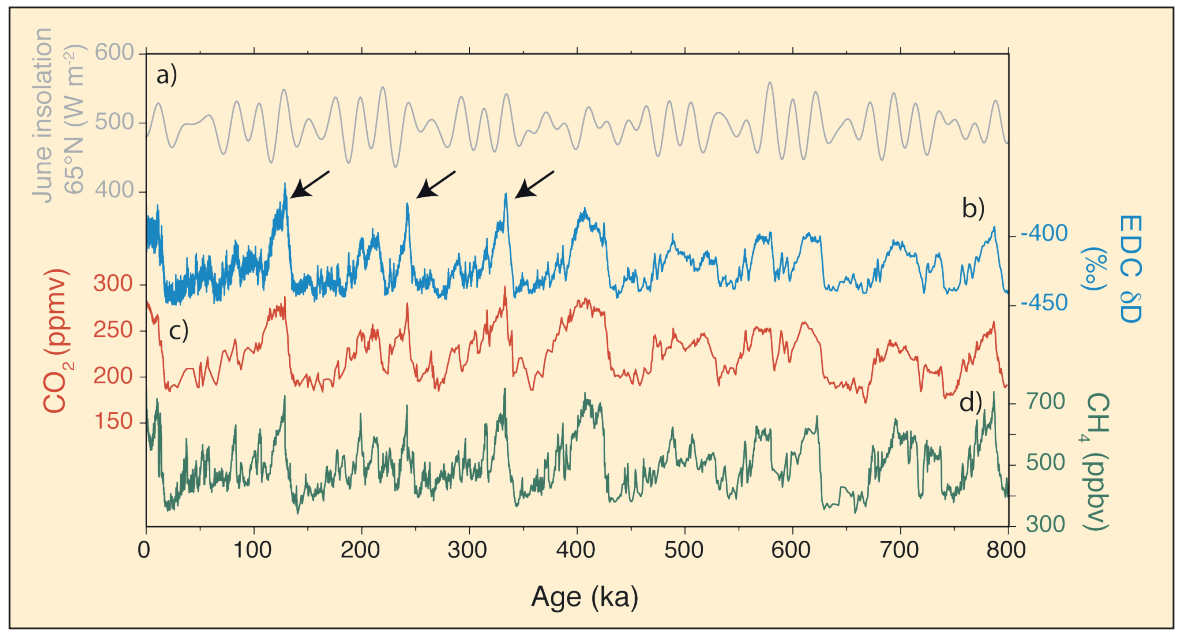

Figure 1: EPICA Dome C (EDC) ice core records plotted against a) June insolation for $65^{\circ} \mathrm{N}$ (Berger, 1978). EDC records are (b) deuterium ( $\delta D$ ) composition of the ice (Jouzel et al., 2007); (c) atmospheric CO, concentration (Lüthi et al., 2008); (d) atmospheric $\mathrm{CH}_{4}$ concentration (Loulergue et al., 2008). Black arrows indicate relatively short-lived maxima in temperature ( $\delta D)$ and greenhouse gas concentrations that were discussed in depth at the meeting.

At the second PIGS workshop held at the University of the Aegean, on the Island of Lesvos (24 - 27 August, 2009), 25 scientists from 10 countries (including $2 \mathrm{PhD}$ students, 3 young scientists, and 7 newcomers to PIGS), representing the marine, ice core, terrestrial and modeling communities, met to assess our current understanding of the following issues: (i) evidence for intra-interglacial variability; (ii) (relative) timing and local or regional significance of reported events; (iii) transient jumps and declines in temperature and greenhouse gas (GHG) concentrations at the onset of interglacials (Fig. 1); (iv) comparison of interglacial and glacial climate instability.

The first day focused on general considerations of interglacial trends and variability. Ice core data (Antarctic temperatures and GHGs) were examined first, along with atmospheric $\mathrm{CO}_{2}$ reconstructions beyond $800 \mathrm{ka}$. This was followed by presentations of modeling results of interglacial climates and simulations of $\mathrm{CO}_{2}$ concentrations. After a presentation of the potential of specific molecular markers to reconstruct paleofires, the discussion moved to an evaluation of interglacial climate (in)stability and associated mechanisms from paleoceanographic data and reviews from the Mediterranean and the tropical Pacific, as well as sea-level reconstructions.

The presentations of the second day focused on specific case studies: Holocene millennial-scale oscillations in ocean circu- 


\section{S.J.A. Jung, D. Kroon, G. Ganssen, F. Peeters and R. Ganeshram}

Altabet, M.A., Higginson, M.J. and Murray, R.W., 2002: The effect of millennial-scale changes in the Arabian Sea denitrification on atmospheric $\mathrm{CO}_{2}$, Nature, 415: 159-162.

Barker, S., Diz, P., Vautravers, M., Pike, J., Knorr, G., Hall, I.R. and Broecker, W.S., 2009: Interhemispheric Atlantic seesaw response during the last deglaciation, Nature, 457: doi: 10.1038 /nature 07770 .

Blunier, T., et al., 1998: Asynchrony of Antarctic and Greenland climate change during the last glacial period, Nature, 394: 739-743.

Blunier, T. and Brook, E.J., 2001: Timing of millennial-scale climate change in Antarctica and Greenland during the last glacial period, Science, 291: 109-112.

Charles, C.D. and Fairbanks, R.G., 1992: Evidence from Southern Ocean sediments for the effect of North Atlantic deep-water flux on climate, Nature, 355: 416-419.

EPICA, 2006: One-to-One coupling of glacial climate variability in Greenland and Antarctica, Nature, 444: 195-198.

Ivanochko, T.S., Ganeshram, R.S., Brummer, G.-J.A., Ganssen, G., Jung, S., Moreton, S.G. and Kroon, D., 2005: Variations in tropical convection as an amplifier of global climate change at the millennial scale, Earth and Planetary Science Letters, 235: 302-314.

Jung, S.J.A., Kroon, D., Ganssen, G., Peeters, F. and Ganeshram, R., 2009: Enhanced Arabian Sea intermediate water flow during glacial North Atlantic cold phases, Earth and Planetary Science Letters, 280: 220-228.

Pahnke, K. and Zahn, R., 2005: Southern hemisphere water mass conversion linked to North Atlantic climate variability, Science, 307: 1741-1746.

Schulz, H., von Rad, U. and Erlenkeuser, H., 1998: Correlation between Arabian Sea and Greenland climate oscillation of the past 110,000 years, Nature, 393: 54-57.

Shackleton, N.J., Hall M.A. and Vincent, E., 2000: Phase relationships between millennial-scale events 64,000-24,000 years ago, Paleoceanography, 15: 565-569.

Sloyan, B.M. and Rintoul, S.R., 2001: Circulation, renewal and modification of Antarctic Mode and Intermediate Water, Journal of Physical Oceanography, 31: 1005-1030.

Stocker, T.F. and Johnsen, S.J., 2003: A minimum thermodynamic model for the bipolar seesaw, Paleoceanography, 18: doi: 10.1029/2003PA000920.

Stott, L.D., Timmermann, A. and Thunell, R.C., 2007: Southern Hemisphere and Deep-Sea Warming Led Deglacial Atmospheric $\mathrm{CO}_{2}$ Rise and Tropical Warming, Science, 318:

10.1126/science.1143791. 